\title{
Preliminary Anatomical and Histological Study of Lacrimal Gland in Lori Sheep
}

Mohsen Abbasi ${ }^{1}$, Hamid Karimi ${ }^{2 *}$ and Ahmad Gharzi ${ }^{3}$

${ }^{1}$ Department of Basic Sciences, Faculty of Veterinary Medicine, University of Lorestan, Iran

${ }^{2}$ Department of Basic Sciences, Faculty of Veterinary Medicine, University of Tabriz, Iran

${ }^{3}$ Department of Biology, Faculty of Basic Sciences, University of Lorestan, Iran

\begin{abstract}
The lacrimal gland is an important part of lacrimal apparatus that plays an essential role in eye health. In this research, anatomical and histological structures of lacrimal glands of Lori sheep were evaluated. For this purpose, thirty healthy and mature Lori sheep were selected in slaughterhouse and then lacrimal glands removed. After anatomical and biometrical evaluation, lacrimal glands were fixed and processed for histological sectioning and then sections stained with H\&E, Alcian blue and Periodic acid Schiff methods. The results showed that in this species the lacrimal gland lies in dorso-lateral aspect of orbit on the eyeball. The lacrimal gland is surrounded with a connective tissue containing adipose tissue. The gland shows an irregular-rounded to oval shape and pale brown in color. The mean weight, length, width and thickness of the gland were $1.48 \pm 0.3 \mathrm{gr}, 26.98 \pm 0.37 \mathrm{~mm}, 20.11 \pm 0.31 \mathrm{~mm}$ and $3.58 \pm 0.7 \mathrm{~mm}$, respectively. Histological examinations revealed that the lacrimal gland is lobulated and cells of parenchyme are mixed including serous and mucous cells. Intralobular, interlobular and excretion ducts of the gland are lined with cuboidal, stratified cuboidal and pseudo stratified columnar epithelium, correspondingly. In some ducts goblet cells are present among epithelial cells.
\end{abstract}

Keywords: Lacrimal gland; Lori sheep; Histology; Anatomy

\section{Introduction}

The eye is a complex and highly developed organ which collects light from the surrounding environment, regulates its intensity through a diaphragm, focuses it through an adjustable lens to form an image on retina where this image is converted into a set of electrical signals transmitted to the brain. The eyes are protected in the skull by a bony box called the eye socket (orbit). The wall of this eyeball consists of three layers which have different tasks in the anterior and posterior halves of the organ [1]. One of accessory structures of the eye is the lacrimal apparatus which located superiorly and laterally to each eyeball. Each lacrimal apparatus consists of the lacrimal gland, canalicule, lacrimal sac and naso lacrimal duct [2]. The lacrimal glands are responsible for production of tears which flow over the conjunctiva [1]. The lacrimal gland is responsible for production and secretion of tears which clean and nourish the cornea and help to maintain its health. In many species, the main fraction of tears is produced by lacrimal glands. In cattle and wild buffalo, no difference is observed between left and right glands. Moreover, in these animals no sexual dimorphism is evident in the case of the lacrimal gland [3]. There are adequate researches documenting the anatomy and histology of lacrimal glands in human and some other mammals. In all investigated species, the lacrimal gland has presented more or less a similar histological structure and is a mixed gland consisting of tubulo-acinar units [4]. There is a lack of literature on the lacrimal gland in this breed of sheep, our research will contribute to the comparative anatomy and histology and help to understanding the structure of this gland. Moreover, many chemical components in the tear have been documented [5-9]. In current study, the anatomical and histological structure of these glands Lori sheep is scrutinized.

\section{Materials and Methods}

In this study, 15 male and 15 female adult apparently healthy head (without any eye disease) of Lori sheep just after slaughter were selected in Khorramabad slaughterhouse. To dental condition, age of sheep were over than one years. Lacrimal glands were removed. The healthy samples were identified according morphological characters [10]. To make sure the samples are really healthy the samples once again were carefully examined in the laboratory. Eyeballs were removed from orbits cutting off the skin and surrounding tissues. Extensive care was employed to avoid any damage to lacrimal glands. Then the glands were measured biometrically. During the biometric measurements, the weight and dimensions of the gland including the gland's length (the medio-lateral edge), width (the rostro-caudal edge) and thickness (the dorso-ventral edge) were recorded. Moreover, the thickness of the gland's medial part was measured. The measuring of weight and length was made by a scale and Vernire caliper with an accuracy of $0.01 \mathrm{~g}$ and $0.01 \mathrm{~mm}$, respectively.

Following the measurements, a cannula with one-millimeter diameter was inserted into the lacrimal punctum and lacrimal sac. By flushing water into this punctum, the exit opening of the naso lacrimal duct was distinguished. Moreover, length of nasolacrimal duct was measured by inserting the cannula all the way through the duct. All data provided from these measurements were then analyzed by the germinal linear models procedure of SPSS software (version 11.5, SPSS Inc, Chicago, USA). Means were separated by Duncan's Multiple range test and significance was accepted at $\mathrm{p}<0.05$. Later the samples were fixed with formalin saline and then processed for preparing histological sections. Five to seven micrometer sections were cut using a rotary microtome and they were then stained by Hematoxylin and Eosin and Periodic Acid Schiff (PAS), Alcian Blue (pH 2.5) methods.

*Corresponding author: Hamid Karimi, Department of Basic Sciences, Faculty of Veterinary Medicine, University of Lorestan, Iran, Tel: +98 411330 0819; E-mail: karimi@tabrizu.ac.ir; hkarimi1347@yahoo.com

Received November 28, 2013; Accepted January 24, 2014; Published January 27,2014

Citation: Abbasi M, Karimi H, Gharzi A (2014) Preliminary Anatomical and Histological Study of Lacrimal Gland in Lori Sheep. J Veterinar Sci Technol 5: 154. doi:10.4172/2157-7579.1000154

Copyright: ( 2014 Abbasi M, et al. This is an open-access article distributed under the terms of the Creative Commons Attribution License, which permits unrestricted use, distribution, and reproduction in any medium, provided the original author and source are credited. 


\section{Results}

In Lori sheep the lacrimal gland is pale brown in color and irregular oval to spherical in shape located on the dorsolateral surface of the eyeball. The gland displays a lobular appearance and is encompassed by a connective tissue through which in connects to the orbit (internal surface of the frontal bone) dorsally and to the eyeball ventrally (overlaps the rectus dorsalis muscle). Lacrimal gland is compressed between the orbit and the eyeball (Figure 1). As a result of this compression, the dorsal surface of the gland is convex while its ventral surface is concave. This difference in the shape of dorsal and ventral surfaces is clearly evident in fixed specimens. In some samples a part of the lacrimal gland is surrounded by an adipose tissue found around the eyeball. Biometric data relating to Lori sheep's lacrimal gland have been summarized in Table 1.

The excretory duct of the lacrimal gland opens over conjunctiva on the internal surface of the upper lid. The lacrimal puncta of upper and lower lids are in the medial angle of eyes. The color of these puncta varies according to the color of skin sample. Lacrimal canals start from upper and lower lacrimal puncta and after merging together lead to the medial angle of the eye (Figure 2).

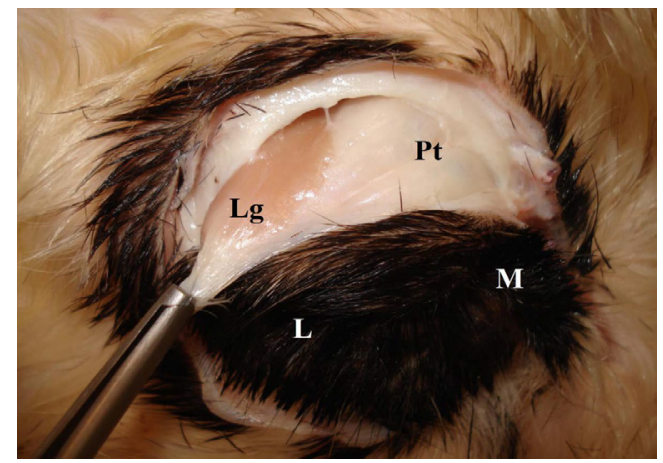

Figure 1: A photograph displaying situation of the lacrimal gland in a Lori sheep eye. The upper part of the eye has been dissected to expose the gland $(\mathrm{Lg})$ which is located on the orbit and in a dorsolateral situation to the eyeball. The surrounding connective tissue $(\mathrm{Pt})$ and lateral $(\mathrm{L})$ and medial $(\mathrm{M})$ corners of the eye is observed.

\begin{tabular}{|l|c|c|c|}
\hline Characters & Minimum & Maximum & Mean \pm SE \\
\hline Weight $(\mathrm{gr})$ & 0.90 & 2.54 & $1.48 \pm 0.3$ \\
\hline Length $(\mathrm{mm})$ & 21.06 & 34.39 & $26.98 \pm 0.37$ \\
\hline Width $(\mathrm{mm})$ & 14.56 & 25.38 & $20.11 \pm 0.31$ \\
\hline Thickness $(\mathrm{mm})$ & 2.33 & 5.20 & $3.58 \pm 0.7$ \\
\hline
\end{tabular}

Table 1: Biometric characteristics of lacrimal glands provided from all specimens.

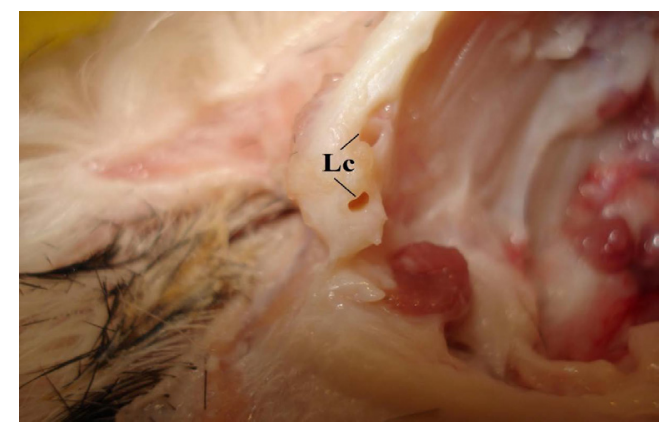

Figure 2: A photograph showing the openings of the lacrimal gland $(\mathrm{Lc})$ in the medial corner of the eye.

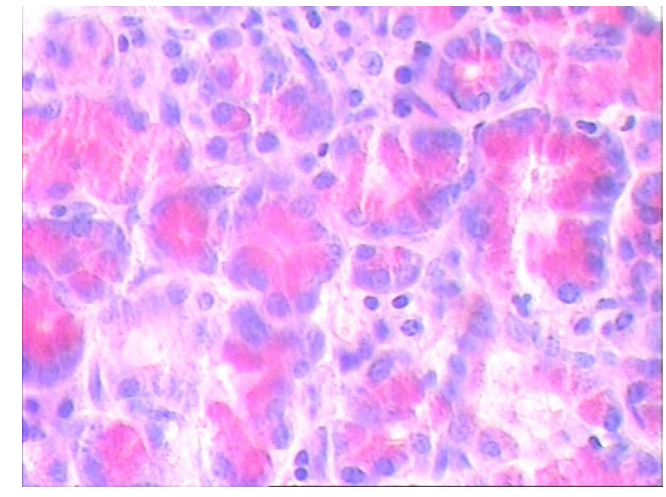

Figure 3: A micrograph displaying mucous acini in higher magnification. The components (red) of these acini show a high affinity to PAS.( PAS staining, $\times 200)$.

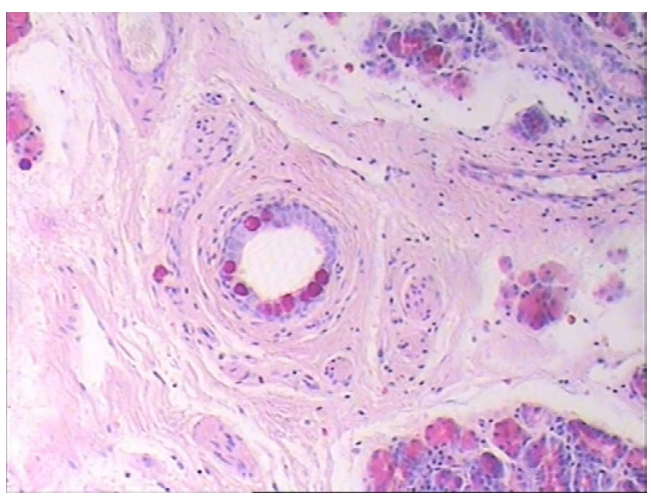

Figure 4: A histological section showing mucous acini and goblet cells (purple) in the linning epithelium of interlobular ducts. (PAS staining, $\times 100$ ).

The lacrimal sac is situated in the medial corner of the orbit (within the lacrimal bone). A nasolacrimal duct extends from the sac to the nostril. This duct shows a mean length of $12.57 \mathrm{~cm}$ and runs in a direct pathway through the maxillae. The minimum and maximum length of this duct in Lori sheep was 10.8 and $14.3 \mathrm{~cm}$, respectively. The end of the nasolacrimal ducts opens into lateral surface of nasal cavity. This opening was on average $1.76 \mathrm{~cm}$ away from the nostril. The minimum and maximum space between the exit opening of the nasolacrimal duct and the nostrils was measures to be 1.4 and $2.4 \mathrm{~cm}$, correspondingly. The nasolacrimal opening is situated over the medial surface of the nasal alar fold. The size of this opening was not the same in all specimens as in some it was hardly observable but in others it was clearly distinguished. In Lori sheep there is no difference in size between the left and right nasolacrimal ducts.

Histological examinations of secretory portions of the gland revealed that it is a mixed gland consisting of tubulo-acinar units. Both types of serous and mucous acini are observed (Figure 3). The surrounding connective tissue penetrates into the gland and divides its parenchyma into several lobules (Figure 4). This separating connective tissue is rich in blood vessels and possesses excretory ducts. The size of lobules varies and no clear pattern is found among them. The cells in serous acini are cuboid to low columnar whose rounded nuclei are located near the cell's basal region. The cytoplasm of these cells displays an eosinophilic reaction. The mucous cells have a vacuolar cytoplasm and their elongated nuclei are situated in the cell base. The serous and mucous parts are mixed together but in some areas the serous acini are 


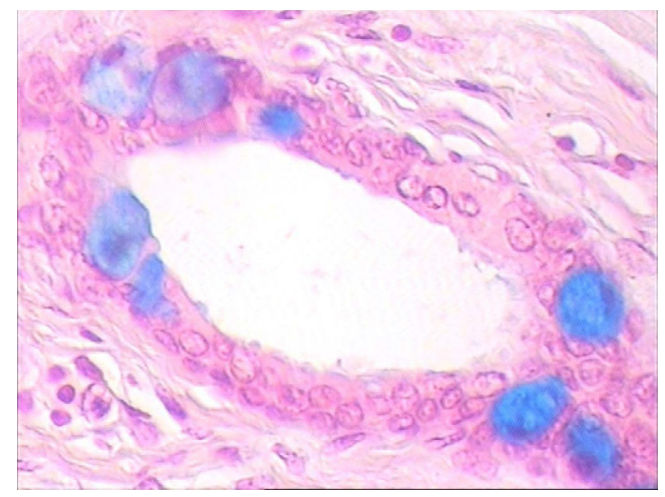

Figure 5: A micrograph showing the histological section of an interlobular duct lined with stratified cuboidal epithelium and goblet cells (blue). Alcian blue staining, $\times 400$.

dominant while in other places the mucous ones are more abundant. Mucous cell contents show a high affinity to PAS and Alcian blue staining (Figure 3). A simple cuboid epithelium lines intralobular ducts, while the epithelial tissue lining interlobular and excretory ducts is stratified cuboidal. In some cases, goblet cells are also seen in these epithelia (Figures 4 and 5). The epithelial tissue which surrounds the lumen of excretory ducts is pseudostratified columnar containing a rich population of goblet cells. The numbers of these cells in interlobular and excretory ducts differ. The diameter of the ducts are also different.

\section{Discussion}

The fluid (tear film) that normally exists in the eye conjunctiva sac and is known as consists of an aqueous layer produced by lacrimal glands and a lipid layer made by glands located in eyelids including tarsal, Zeis and Moll glands [11]. Biochemically, tears film is very complex, composed of an outer layer of lipid and an inner mucous gelatinous layer separated by a medial layer of aqueous fluid. This aqueous layer is made of electrolytes, water, and proteins. These components are principally secreted by the lacrimal gland composed of acini lobules. The lumen of each acinus is lined by columnar epithelial cells. These cells are surrounded by a basal layer of myoepithelial cells enclosed by a basement membrane. The fluid produced by the lacrimal gland through intralobular and interlobular ducts drain into the conjunctival space beneath the upper eyelid [11]. As a result of eyelid movements, the tears fluid flows over the cornea and produce a thin layer of the fluid on the cornea. During the periods between blinks, a slow and continuous evaporation takes place from the corneal surface but the thin layer of lipid produced by tarsal (Meibom) gland to some extent prevents evaporation of the aqueous layer. In some animals the periods between blinks are long and this might result in dry eye syndrome. The lacrimal gland is surrounded by a connective tissue containing collagen fibers and many fibroblasts and divides the gland's parenchyma into lobules [11]. This kind of lobulation is clearly observed in the Lori sheep lacrimal gland. Age-related changes have been reported in the lacrimal system of humans and rats. Gender has no effect on anatomical characteristics of lacrimal glands in cattle whereas these differences have been reported in mice, hamsters, rabbits and humans [3].

Based on histochemical and electron microscopy surveys, three types of secretory cells are observed in this gland; serous, mucous and seromucous cells [4]. In sections obtained from the Lori sheep gland, serous and mucous cells were both identified and thus the gland is a mixed seromucous gland.
These types of mixed seromucous glands have also been reported in many mammals including the pig, horse, goat, hamster. Lacrimal gland of the canine is a mucous gland while in the rat, it is a serious gland. In the sheep the majority of acini contain mixed serous, seromucous and mucous cells [4].

IgA-containing cells have extensively been observed in the lacrimal gland of many species. IgA in tears comes from local synthesis and is not derived from serum [12]. Today, with development of analytical approaches for determining glucose concentration in tear fluid, the glucose is separated from salts and proteins such as lysosyme, globulin and albumin. This approach can be used as a non-invasive method for assessment of glucose concentration in diabetic patients [9]. It has been documented that there is gender differences in the case of lacrimal gland morphology [13].

According to a previous report, in sheep the lacrimal gland is a red flattened and oval-shaped structure which resides within the orbit in a dorsolateral situation to the eyeball and is surrounded by the frontal bone [4]. In the present study, the gland was observed at the same place but its color was different from the previous report. In Lori sheep the gland displayed a light brown color. In the camel, the dorsal and ventral puncta were absent and the lacrimal duct is a blind canal that starts at the medial part of the upper and lower eyelids. In goat and donkey, the dorsal and ventral lacrimal puncta display a slit-like openings which are directed to the lacrimal sac. Nasolacrimal duct with a minor curl at its starting point, pass rostrally through the osseous lacrimal canal and enters the lacrimal, zygomatic and maxillary bones. It passes through the maxillary sinus and then runs through the nasal cavity in a descending and arched manner. At the lateral side of the ventral nasal concha it is only covered by the nasal mucosa and a thin layer of connective tissue. The nasolacrimal ducts opens into the nasal cavity at the lateral side of the nasal vestibule and at the linking point of the mucous membrane and skin. The exit opening is very small in camel and goats but is clearly discernible in donkeys [5]. In sheep, the nasolacrimal duct opens to the nasal cavity on th alar fold with a slim space from the nostril after passing through the lacrimal and maxillary bones.

In one-humped camel, the lacrimal gland resembles other ruminants (with the exception of cattle which has an accessory lobe) and appears as a flattened, elongated, and irregular structure. The dorsal side of the gland is convex, its ventral side is concave and its medial edge is broader than is lateral edges. In cattle, the length and width of the gland is 6070 and $35 \mathrm{~mm}$, respectively. This is considerably larger than the gland found in one-humped camel. It has been reported that in one-humped camel the length of the gland is $49-53 \mathrm{~mm}$ while its width is $19 \mathrm{~mm}$. In sheep the length and width of the gland measured to be 28 and $20 \mathrm{~mm}$, respectively. The current findings are in agreement with previous data. In one-humped camel the left lacrimal gland is significantly larger that the right gland [14]. In Lori sheep no significant difference was observed between the left and the right gland. In one-humped camel, goblet cells are present in stratified epithelium lining interlobular ducts [14]. This kind of cell was also observed in the lacrimal gland of Lori sheep.

In a survey carried out on the human lacrimal gland it was found that in males the glands have significantly been heavier than their counterparts from the females. The mean weight of male glands has been $1.34 \mathrm{gr}$ against $0.96 \mathrm{gr}$ for females. Prevalence of atrophy in female lacrimal glands, which are associated with a dry eye syndrome, may be attributed to this sexual dimorphism [4]. In Lori sheep the male glands were slightly larger than the female gland ( $1.58 \mathrm{gr}$ in male and $1.39 \mathrm{gr}$ in female) but this discrepancy did not have significant differences. This difference may be resulted by the size of the animals. 
Citation: Abbasi M, Karimi H, Gharzi A (2014) Preliminary Anatomical and Histological Study of Lacrimal Gland in Lori Sheep. J Veterinar Sci Technol 5: 154. doi:10.4172/2157-7579.1000154

Page 4 of 4

In rats, the system of lacrimal ducts consists of three parts including intralobular ducts located in each lobe, interlobular ducts observed between lobes and finally the excretory ducts, which are situated outside of the gland. The intralobular ducts are lined by a simple epithelium, which is enclosed by myoepithelial cells. The interlobular ducts are lined by more than a layer of epithelial cells, which display a stratifiedlike appearance [15]. In sheep, the excretory system of lacrimal gland consists of two large and 4-5 small excretory ducts. These ducts open into the front fornix of the upper eyelid conjunctiva. In sheep, these ducts are lined with a stratified columnar epithelium containing many goblet cells [16]. In the present study, such an epithelium was not observed. The tear drainage system varies in different species and even among different individuals of the same species [1].

\section{Conflict of Interest}

The author wishes to thank the research deputy of Lorestan University for its support and also expresses his appreciation to $\mathrm{Mr}$. Pirzadi and Mr. Yavari for their technical assistance and preparation of specimens.

\section{References}

1. Junquira LC, Carneiro J (2003) Basic histology. 10th ed. McGraw- Hill Companies. USA 481-482.

2. Konig HE, Liebich HG (2007) Veterinary anatomy of domestic mammals, textbook and colour atlas. 3rd ed. Germany 588-589.

3. Pinard CL, Weiss ML, Brightman AH, Fenwick BW, Davidson HJ (2003) Normal anatomical and histochemical characteristics of the lacrimal glands in the American bison and cattle. Anatomia Histologia Embryologia 32: 257-262.

4. Gargiulo AM, Coliolo P, Ceccarelli P, Pedini V (1999) Ultrastructural study of sheep lacrimal glands. Vet Res 30: 345-351.
5. Alsafy MAM (2010) Morphological studies on the lacrimal apparatus of onehumped camel, goat and donkey. J of Biological Sciences 10: 224-230.

6. Bigham A, Shadkhast M (2009) Lacrimal apparatus of Iranian river buffaloes (Bubalus bubalis): anatomical study. Vet Scan 4: 23-27.

7. Lorber M, Vidić B (2009) Measurements of lacrimal glands from cadavers, with descriptions of typical glands and three gross variants. Orbit 28: 137-146.

8. Mohammadpour AA (2009) Morphological and histological study of superior lacrimal gland of third eyelid in camel (Camelus dromedarius). Iranian $\mathrm{J}$ of Veterinary Research, Shiraz University 10: 334-338.

9. Taormina CR, Baca JT, Asher SA, Grabowski JJ, Finegold DN (2007) Analysis of tear glucose concentration with electrospray ionization mass spectrometry. $J$ Am Soc Mass Spectrom 18: 332-336.

10. Khaldari M (2008) Sheep and goat husbandry. Jihad Daneshgahi Tehran 132133.

11. Klećkowska-Nawrot J, Dziegiel P (2008) Morphology of lacrimal gland in pig fetuses. Anat Histol Embryol 37: 74-77.

12. Sullivan DA, Allansmith MR (1984) Source of IgA in tears of rats. Immunology 53: 791-799.

13. Cornell-Bell AH, Sullivan DA, Allansmith MR (1985) Gender-related differences in the morphology of the lacrimal gland. Invest Ophthalmol Vis Sci 26: 11701175 .

14. Mohammadpour AA (2008) Anatomical characteristics of dorsal lacrimal gland in one-humped camel (Camelus dromedarius). Journal of Biological Sciences 8: 1104-1106.

15. Alexander JH, Young JA, van Lennep EW (1973) The ultrastructure of the duct system in the rat extraorbital lacrimal gland. Z Zellforsch Mikrosk Anat 144: 453-466.

16. Sisson GR, Grossman (1975) The Anatomy of the Domestic Animals. 5th ed. W. B. Saunders company. 1: 946-954. 